\title{
Septate uterus: incidental finding in multiparous woman with breech with bad obstetric history who had an emergency caesarean
}

\author{
Shilpi Singh $^{1 *}$, Sheela S. R. ${ }^{1}$, Sreeramulu P. N. ${ }^{2}$ \\ ${ }^{1}$ Department of Obstetrics and Gynecology, ${ }^{2}$ Department of Surgery, Sri Devraj Urs Medical College, Tamaka,
} Karnataka, India

Received: 07 April 2018

Accepted: 30 April 2018

*Correspondence:

Shilpi Singh,

E-mail: shilpi_dudu@yahoo.co.in

Copyright: ( $\odot$ the author(s), publisher and licensee Medip Academy. This is an open-access article distributed under the terms of the Creative Commons Attribution Non-Commercial License, which permits unrestricted non-commercial use, distribution, and reproduction in any medium, provided the original work is properly cited.

\begin{abstract}
The most common anomalies of reproductive tract are Mullerian duct anomalies, among which septate uterus is the commonest with highest reproductive failure rate. As there are some pitfalls in diagnosis therefore the incidence is difficult to be mentioned as many remain asymptomatic. A 20 year old G5P1L0A3 with $36+4$ weeks of gestation with breech presentation in active labour came to our hospital. Patient had previous history of intrauterine death at 8 months of amenorrhea and previous abortions at 5, 5 and 4 months of amenorrhoea in the year 2011, 2013, and 2014 respectively. She underwent emergency caesarean section due to breech at $36+4$ weeks in active labour with the delivery of a live late preterm female baby extracted by complete breech of weight $2.28 \mathrm{kgs}$ with bilateral CTEV of the baby. Intraoperative findings- of septate uterus-septum extending from fundus to external os, fundal dimpling present. Though rare but uterine anomalies should be suspected in patients with recurrent pregnancy loss, preterm birth and malpresentation.
\end{abstract}

Keywords: CTEV, Malpresentation, Recurrent pregnancy loss, Septate uterus

\section{INTRODUCTION}

Mullerian duct anomalies are the most common congenital anomalies of the female reproductive tract in which septate uterus is the most common found being 2 $3 \%$ with highest reproductive failure rate. ${ }^{1}$ It is most commonly associated with adverse pregnancy outcome and seen in in patients with recurrent pregnancy loss. ${ }^{2}$ But the association between two have been retrospectively diagnosed in cases of unexplained infertility. These anomalies are usually detected in first trimester ultrasonography. ${ }^{3}$ Recently three-dimensional ultrasonography is considered the gold standard for diagnosing uterine anomalies and seems to have replaced endoscopy. ${ }^{4,5}$ Need for treatment arises when patient complains of hematometra, recurrent abortions, infertility or dysmenorrhoea. ${ }^{6}$ It is because of this that a case report on septate uterus, an incidental finding in a multiparous woman who had an emergency caesarean section, is necessary.

\section{CASE REPORT}

Mrs. X was a 20 years old patient gravida 5, para 1, living 0 , abortion 3 with 36 weeks 4 days gestational age with breech presentation in active labour presenting in our hospital in obstetric emergency room with complaints of pain abdomen, intermittent in nature radiating to thighs and back. No other complaints. Patient had married life of 6 years with previous history of 3 abortions at 5,5,4 months of amenorrheoa respectively and history of intrauterine death at $8^{\text {th }}$ month of amenorrhoea. Patient did not have any previous ultrasound reports of this pregnancy as well as previous pregnancy. On 
examination, per abdomen uterus was 36 weeks size, breech, uterus acting 2-3c/20'/10" FHR was present with heart rate of $148 \mathrm{bpm}$ regular. Per vagina- cervix soft 4 $\mathrm{cm}$ dilated, $50 \%$ effaced, membranes present, PP breech 1 station.

\section{Operative findings}

Patient was taken for emergency caesarean section in view of breech at $36+4$ weeks of gestation in active labor with bad obstetric history and cesarean delivery at maternal request.

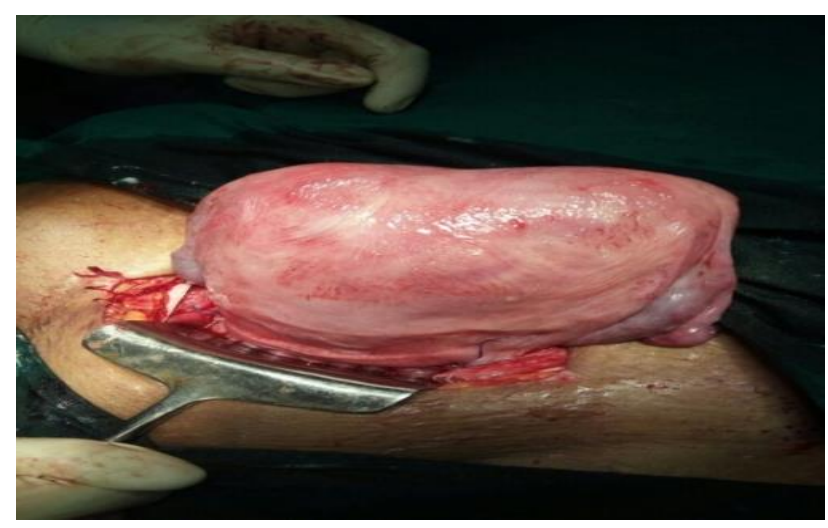

Figure 1: Fundal dimpling.

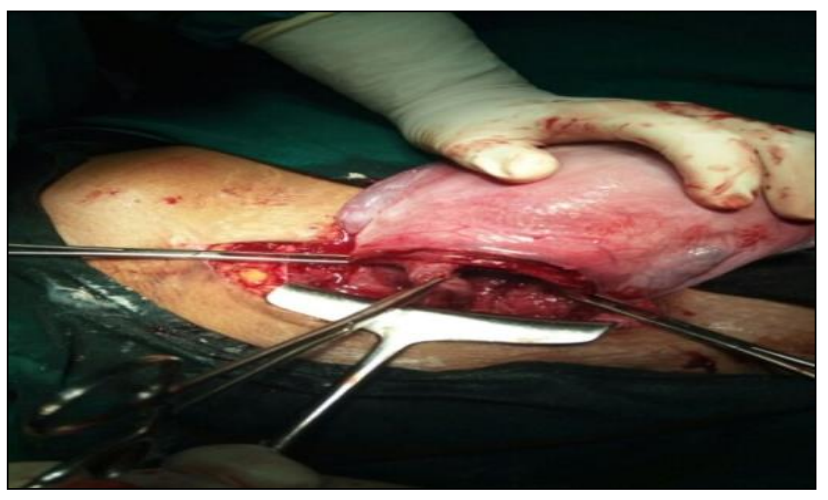

Figure 2: Septate uterus extending from the fundus to internal OS.

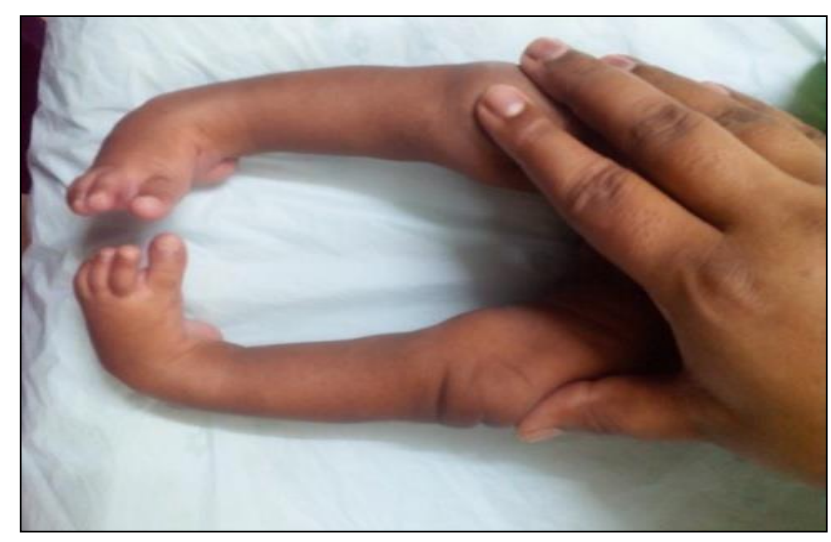

Figure 3: Bilateral CTEV.
Extracted by complete breech a live late preterm female baby of weight $2.28 \mathrm{kgs}$ with bilateral CTEV (Figure 3) of the baby. Per operative findings were-Lower uterine segment was well formed. Septate uterus-extending from the fundus to internal os present (Figure 2), fundal dimpling was present (Figure 1)

\section{DISCUSSION}

A uterine septum is a one where the uterine cavity is partitioned by a longitudinal septum. Uterine serosal surface has a normal typical shape. Septate uterus can be two types either complete or partial according to American Society Of reproductive Medicine. The wedgelike partition may involve only the superior part of the cavity resulting in an incomplete septum or a subseptate or partial uterus, or sometimes the total length of the cavity (complete septum). A complete septate variety was found in this patient. The septation continued caudally into the vagina resulting in a double vagina. These developmental anomalies may be associated with recurrent pregnancy loss, preterm labour, malpresentation, and infertility. The patient presented with these complications.

The condition may not be known to the affected individual and maybe asymptomatic; thus normal pregnancies may occur, as it is for the case being presented. Transvaginal 3-dimensional ultrasonography appears to be extremely accurate for the diagnosis and classification of congenital uterine anomalies, better than hysteroscopy and MRI. It may become the only mandatory step in the assessment of the uterine cavity in patients with a suspected septate or bicornuate uterus? ${ }^{7}$.

However, Mrs X did not have the benefit of an ultrasound scan during pregnancy that might have suggested this diagnosis. If she had an obstetric ultrasound scan, it would have been with a two-dimensional ultrasound machine which has low precision in differentiating between arcuate, bicornuate and septate anomaly due to restricted view and assessment of the uterine fundus8. This patient carried the pregnancy to term, as longer uterine septa have increased vascularity and thus supports pregnancy better ${ }^{9}$.

The place of surgery for the septum is putative. Some authors belief it should not be removed if detected in asymptomatic patient undergoing routine evaluation for infertility or non-infertility related indications. On the other side, some authors believe that it is not reasonable to expose infertility patients with septum to high risk of miscarriage when she finally gets pregnant 10 . However, there is a consensus of opinion that surgery should be done when septate uterus is detected in women with recurrent pregnancy loss. Hysteroscopic septoplasty is highly favoured procedure resulting in low morbidity and improvement in pregnancy outcomes 11 . In this case, we did not contemplate removing the septum because the caesarean section was an emergent intrapartum one with 
likelihood of genital sepsis that may complicate healing. The effect of undiagnosed uterine septum was seen in the baby of the patient and thus she may have benefited from surgical intervention if diagnosed before conception.

The baby was referred to the orthopaedic surgeons for management.

\section{CONCLUSION}

Though rare but uterine anomalies should be suspected in patients with recurrent pregnancy loss, preterm birth and malpresentation.

\section{Funding: No funding sources}

Conflict of interest: None declared

Ethical approval: Not required

\section{REFERENCES}

1. Pang, LH, Li MJ, Li MQ, Xu, H, Wei, ZL. Not Every Subseptate Uterus Requires Surgical Correction to Reduce Poor Reproductive Outcome. Int J of Gynecol Obstet. 2011;115:260-63.

2. Saravelos SH, Cocksedge KA, Li TC. Prevalence and diagnosis of congenital uterine anomalies in women with reproductive failure: a critical appraisal. Hum Reprod Update. 2008;14:415-29.

3. Nagrathanamma R, James T, Prasad N. Pregnancy Outcome in Uterine Anomalies. J Med Sci. 2017;3(1):31-3.

4. Ghi T, Casadio P, Kuleva M, Perrone AM, Savelli L, Giunchi S, et al. Accuracy of three-dimensional ultrasound in diagnosis and classification of congenital uterine anomalies. Fertil Steril. 2009;92:808-13.
5. Bermejo C, Martinez TP, Cantarero R, Diaz D, Pe'rez Pedregosa J, Barro`n E et al. Threedimensional ultrasound in the diagnosis of Mullerian duct anomalies and concordance with magnetic resonance imaging. Ultrasound Obstet Gynecol. 2010;35:593-601.

6. Chang AS, Siegel CL, Moley KH, Ratts VS, Odem RR. Septate uterus with cervical duplication and longitudinal vaginal septum: a report of five new cases. Fertil Steril 2004;81:1133-36.

7. Faivre E, Fernandez H, Deffieux X, Gervaise A, Frydman R, Levaillant JM. accuracy of threedimensional ultrasonography in differential diagnosis of septate and bicornuate uterus compared with office hysteroscopy and pelvic magnetic resonance imaging. J Minim Invasive Gynecol. 2012;19:10106.

8. Nicolini U, Bellotti M, Bonazzi B, Zamberletti D. Candiani GB. Can Ultrasound Be Used to Screen Uterine Malformations? Fertil Steril.1987;47:89-93.

9. Dabirashrafi H, Bahadori M, Mohammad K, Alavi M, Moghadami-Tabrizi N, Zandinejad K et al. Septate uterus: new idea on the histological features of the sepyum in this abnormal uterus. Am $\mathrm{J}$ of Obstet Gynecol. 1995;171:105-7.

10. Balen AH. Tubal infertility and fibroid. In: infertility in practice, Informa, London. 2008:239-257.

11. Homer HA, Li TC, Cooke ID. The septate uterus: A review of management and reproductive outcome. Fertil Steril. 2000;73:1-14.

Cite this article as: Singh S, Sheela S. R., Sreeramulu P. N. Septate uterus: incidental finding in multiparous woman with breech with bad obstetric history who had an emergency caesarean Int J Reprod Contracept Obstet Gynecol 2018;7:2512-4. 